PREPARED FOR THE U.S. DEPARTMENT OF ENERGY, UNDER CONTRACT DE-AC02-76CH03073

PPPL-3884

PPPL-3884

UC-70

Advanced Tokamak Plasmas

in the Fusion Ignition Research Experiment

by

C.E. Kessel, D. Meade, D.W. Swain, P. Titus, and M.A. Ulrickson

October 2003

N/W

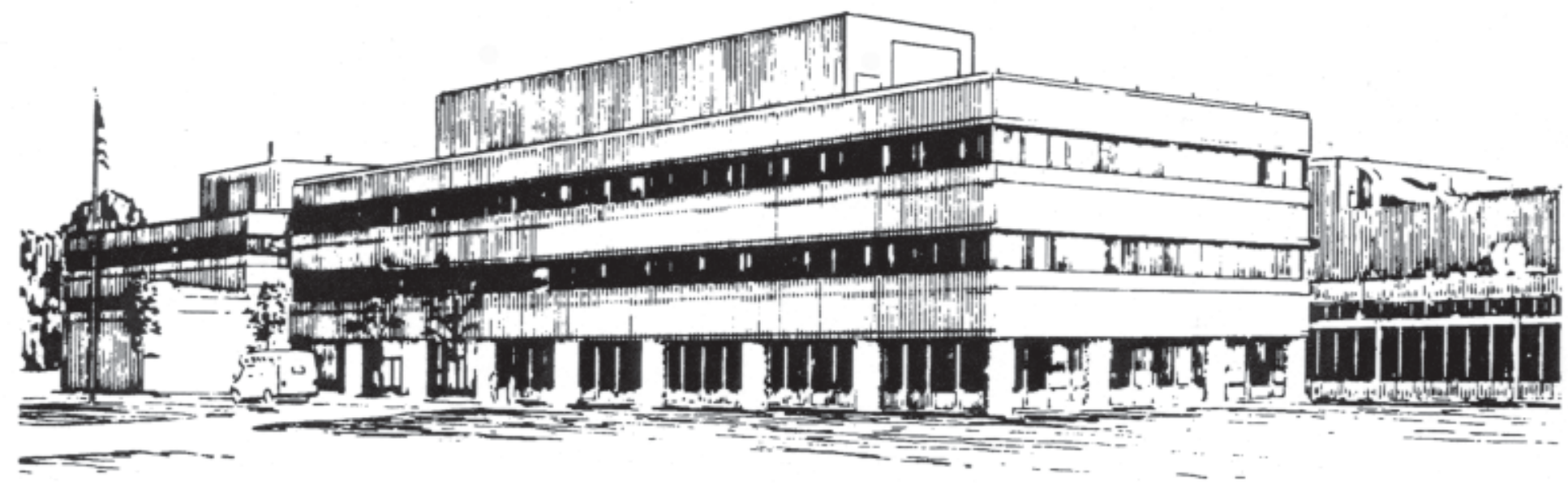

PRINCETON PLASMA PHYSICS LABORATORY PRINCETON UNIVERSITY, PRINCETON, NEW JERSEY 


\section{PPPL Reports Disclaimer}

This report was prepared as an account of work sponsored by an agency of the United States Government. Neither the United States Government nor any agency thereof, nor any of their employees, makes any warranty, express or implied, or assumes any legal liability or responsibility for the accuracy, completeness, or usefulness of any information, apparatus, product, or process disclosed, or represents that its use would not infringe privately owned rights. Reference herein to any specific commercial product, process, or service by trade name, trademark, manufacturer, or otherwise, does not necessarily constitute or imply its endorsement, recommendation, or favoring by the United States Government or any agency thereof. The views and opinions of authors expressed herein do not necessarily state or reflect those of the United States Government or any agency thereof.

\section{Availability}

This report is posted on the U.S. Department of Energy's Princeton Plasma Physics Laboratory Publications and Reports web site in Fiscal Year 2004. The home page for PPPL Reports and Publications is: http://www.pppl.gov/pub_report/

DOE and DOE Contractors can obtain copies of this report from:

U.S. Department of Energy

Office of Scientific and Technical Information

DOE Technical Information Services (DTIS)

P.O. Box 62

Oak Ridge, TN 37831

Telephone: (865) 576-8401

Fax: (865) 576-5728

Email: reports@adonis.osti.gov

This report is available to the general public from:

National Technical Information Service

U.S. Department of Commerce

5285 Port Royal Road

Springfield, VA 22161

Telephone: $1-800-553-6847$ or

(703) $605-6000$

Fax: (703) 321-8547

Internet: http://www.ntis.gov/ordering.htm 


\title{
Advanced Tokamak Plasmas in the Fusion Ignition Research Experiment
}

\author{
C. E. Kessel, D. Meade, D. W. Swain ${ }^{\mathrm{a}}$, P. Titus ${ }^{\mathrm{b}}$, M. A. Ulrickson ${ }^{\mathrm{c}}$ \\ Princeton Plasma Physics Laboratory, P.O. Box 451, Princeton, NJ 08534 \\ ${ }^{a}$ Oak Ridge National Laboraotiry, P.O. Box 2009, Oak Ridge, TN 37831 \\ ${ }^{b}$ Massachussetts Institute of Technology, 175 Albany St., Cambridge, MA 02139 \\ ${ }^{c}$ Sandia National Laboratory, P.O. Box 5800, Alburquerque, NM 87185
}

\begin{abstract}
The Advanced Tokamak capability of the FIRE burning plasma experiment is examined with OD systems analysis, equilibrium and ideal MHD stability, RF current drive analysis, and full discharge dynamic simulations. These analyses have identified the required parameters for attractive burning AT plasmas, and indicate that these are feasible within the engineering constraints of the device.
\end{abstract}

\section{INTRODUCTION}

The Fusion Ignition Research Experiment (FIRE) is a high field compact tokamak burning plasma experiment, utilizing copper TF and PF coils. The project is examining the advanced tokamak (AT) capability of the device. The AT is envisioned as a sequence of configurations with progressively higher $\beta \mathrm{N}$, higher bootstrap/noninductive current fraction, for extended pulse lengths, and with more sophisticated plasma control. In order to obtain extended pulse lengths the toroidal field is lowered to the range of 6.5-7.0 T, although the fusion power remains similar to the reference $\mathrm{H}$-mode operating point, so that nuclear heating limits the flattop time to $31 \mathrm{~s}$ at $150 \mathrm{MW}$ of fusion power. Increasing $\beta \mathrm{N}$ requires first stabilizing the neoclassical tearing modes, allowing access to $\beta \mathrm{N}$ above 1.5-2.5. Stabilization of the $\mathrm{n}=1$ resistive wall mode allows access to $\beta \mathrm{N}$ values about 4.3-5.5. The $\mathrm{n}>2$ resistive wall modes might limit access to the high $n=1 \beta$ limit to values about 3.7-5.0. The bootstrap or noninductive current fraction is increased by raising the $\beta \mathrm{N}$, using external current drive sources (ICRF/FW, LHCD), and control of the density and temperature profiles. The control of temperature and density profiles inside the plasma is directly tied to research on internal transport barriers (ITB), and is an active area for tokamak theory and experiments.

The primary focus of AT scenarios for FIRE are quasistationary burning plasmas. The plasma current is to be driven noninductively in flattop, although inductive drive is used in conjunction with noninductive current drive during the rampup. The plasma safety factor is required to be quasistationary for the flattop phase, and held by the combination of bootstrap current, and lower hybrid and fast wave current drive sources. The flattop times obtained by lowering the toroidal field are typically 2-5 times the current diffusion time in these plasmas. Since these are burning plasmas, the target is fusion gains $(\mathrm{Q}=$ Pfus $/$ Paux $) \geq 5$.

\section{SYSTEMS ANALYSIS OF ADVANCED TOKAMAK PLASMAS}

A zero-dimensional systems code was developed for use in the FIRE study. The analysis used for AT operating point calculations incorporates the plasma power and particle balance, plasma flux consumption, in addition to several other global parameter relations. In particular, the ITER98 $(y, 2)$ scaling is assumed for the global energy confinement time. For the present application to AT plasmas, the major and minor radius, and elongation, triangularity and aspect ratio are fixed. These have been set by the reference ELMy H-mode inductively driven design point; $\mathrm{R}=2.14 \mathrm{~m}, \mathrm{a}=0.595 \mathrm{~m}$, $\kappa(X p t)=2.0, \quad \delta(X p t)=0.7, A=3.6$. An expression for the bootstrap current fraction is included and the current drive power is given by $\mathrm{P}_{c d}=[\mathrm{nRIp}(1-\mathrm{fbs})] / \eta_{\mathrm{cd}}$. The on-axis current drive is fixed at $200 \mathrm{kA}$ from ICRF/FW, so that $\mathrm{LH}$ must make up any current not driven by the bootstrap effect. The current drive efficiency used in these scans is $\eta c d=0.2$ and $0.16 \mathrm{~A} / \mathrm{W}-\mathrm{m} 2$ for ICRF/FW and $\mathrm{LH}$, respectively, and is based on detailed LH and ICRF/FW analysis for FIRE. A large number of plasma configurations are generated by varying the toroidal field (from 6.5-8.5 T), q95 (from 3.1-5.0), peak to average density (from 1.25 to 2.0 ), $\beta \mathrm{N}$ (from 2.5-5.0), density divided by Greenwald density $\mathrm{n} / \mathrm{nGr}$ (from $0.45-1.0$ ), and impurity content composed of $\mathrm{Be}$ and Ar. Here the Greenwald density is defined as $\mathrm{nGr}=\mathrm{Ip} / \pi \mathrm{a}^{\wedge} 2$ The acceptable solutions are constrained to have a given $\mathrm{Q}$ value, the external current drive power must be less than the total auxiliary power injected into the plasma, the first wall surface heat flux is limited to less than $1.0 \mathrm{MW} / \mathrm{m}^{2}$ with a peaking factor of 2 , the total particle power to the divertor must be less than 28 MW, and the radiated plus particle heat load to the divertor and baffle must be less than $6-8 \mathrm{MW} / \mathrm{m}^{2}$.

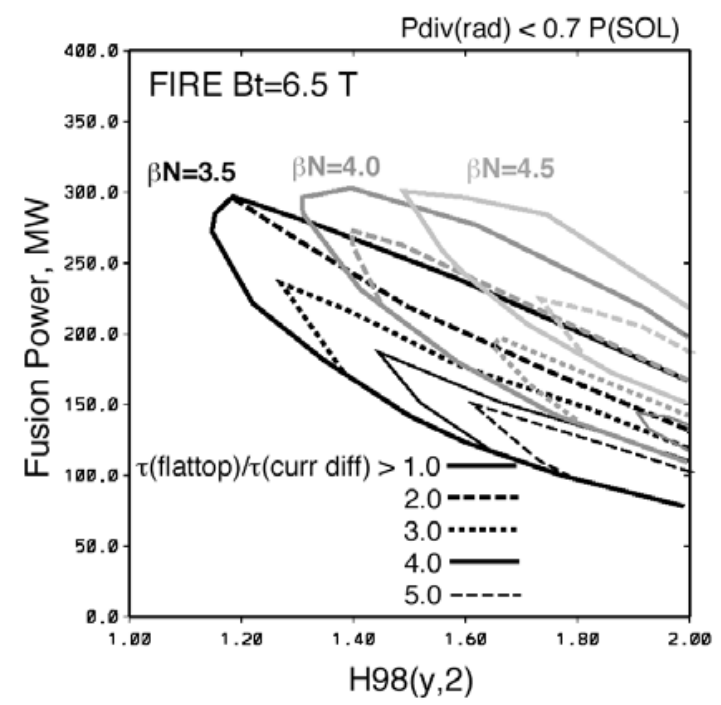

FIGURE 1. The fusion power versus the required $\mathrm{H} 98$ confinement multiplier for plasmas at $\mathrm{Bt}=6.5 \mathrm{~T}, \beta \mathrm{N}=3.5-4.5$, and $\mathrm{Q}=5$. The power radiated in the divertor is less than $70 \%$ of the power that enters the SOL. The number of current diffusion times accessible are displayed. 
Shown in Figure 1 is the fusion power as a function of the $\mathrm{H} 98$ factor, for $\mathrm{B}_{\mathrm{T}}=6.5 \mathrm{~T}, \beta \mathrm{N}=3.5-4.5$, and $\mathrm{Q}=5$. The available operating space is inside the curves, and they show the number of current diffusion times in the flattop and different $\beta_{\mathrm{N}}$ values. From these curves the required confinement time multiplier increases as we approach more current diffusion times in the flattop or higher $\beta_{\mathrm{N}}$ 's. The curves with the lowest confinement multipliers are at the highest densities and most peaked density profiles. Another critical parameter for these AT plasmas is the fraction of power radiated in the divertor, with larger fractions significantly enlarging the operating space. This is because the auxiliary power associated with the $C D$ increases the total power that must be handled by radiation to the first wall, direct particle power to the divertor, and radiated power on the divertor and baffle. Overall, FIRE has a significant operating space for AT plasmas with energy confinement already demonstrated in experimental DIII-D AT plasmas, and this serves as the basis for more detailed plasma simulations.

\section{PLASMA EQUILIBRIUM AND STABILITY}

Equilibrium and ideal MHD stability analyses are done to determine what plasmas can be produced and what their achievable $\beta$-limits are. The JSOLVER[1] fixed boundary flux coordinate equilibrium code is used with self-consistent bootstrap current. The BALLOON[2] and PEST2[3] codes are used for $n=\infty$ and $n=1-3$ stability calculations, respectively. In addition, the VACUUM code is used to treat the presence of the vacuum vessel and $\mathrm{Cu}$ conductors.

The plasma configurations all have reversed shear[4] current and safety factor profiles. It is found that the LHCD, which defines the minimum in the safety factor, penetrates to $\mathrm{r} / \mathrm{a}$ of 0.6-0.8 for typical FIRE temperatures and densities. Equilibrium calculations are done using the current profiles from RF analysis and the bootstrap current is calculated selfconsistently. Both L-mode and H-mode edge conditions are examined, with the H-mode providing additional bootstrap current near the plasma edge due to the pedestal pressure gradient.

The FIRE vacuum vessel has a $1.5 \mathrm{~cm}$ thick copper cladding adhered to it, along with the $2.5 \mathrm{~cm}$ thick copper passive stabilizers for the vertical stability located above ports on the outboard side and behind the inboard divertor. These conductors will slow the kink modes down and transform them into resistive wall modes. FIRE will utilize active feedback control of these resistive wall modes by placing window coils on the ends of the various port plugs, bringing them very close to the plasma. This approach is based on the theoretical studies[5] and experiments in HBT-EP and DIII$\mathrm{D}[6,7]$. Stability calculations for $\mathrm{n}=1,2$, and 3 kink modes are done assuming a superconducting wall on the outboard side of the plasma, spanning poloidally from $-90^{\circ}$ to $+90^{\circ}$ measured from the plasma major radius. The location of the actual wall is at 0.25 times the minor radius from the plasma boundary on the outboard side, however there are ports on the midplane which remove a considerable amount of the conductor, so that the wall is approximated by shifting it to 0.35. Shown in Figure 2 is the achievable $\beta_{\mathrm{N}}$ both ignoring the vacuum vessel and $\mathrm{Cu}$ cladding's influence and including it, with L-mode and H-mode edge assumptions. The curve labelled "no wall" refers to no conductors outside the plasma. The 3D electromagnetics code VALEN[7] is used to represent the vacuum vessel and $\mathrm{Cu}$ conductors accurately and includes the effects of feedback coils for stabilization of the $n=1$ RWM. In this case, the feedback scheme involves placing feedback window coils around the periphery of each/or every other midplane port and accesses $80-90 \%$ of the $n=1$ ideal "with wall" stability limit. Further VALEN and PEST2 analysis will refine the feedback coil design and determine the impact of the $n=2$ and 3 modes in limiting access to the $n=1$ limit. The access to the higher $\beta \mathrm{N}$ by RWM stabilization allows the bootstrap current fraction to exceed $75 \%$, and would provide attractive examples of burning AT plasmas.

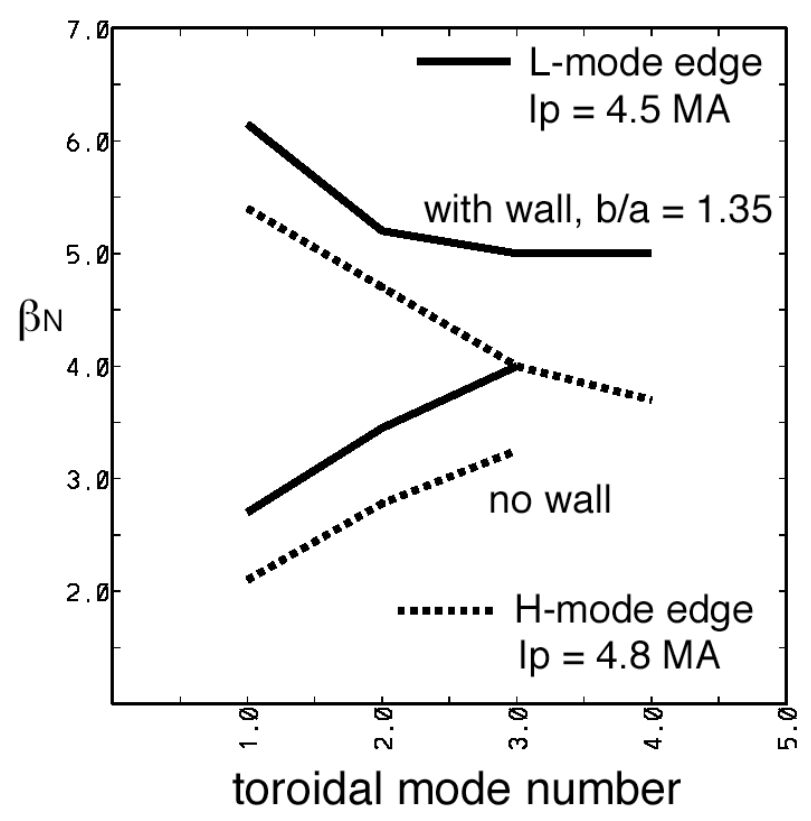

FIGURE 2. Maximum $\beta_{\mathrm{N}}$ values for the $\mathrm{n}=1-4$ external kink modes both with and without a wall at $\mathrm{b} / \mathrm{a}=1.35$.

\section{RF CURRENT DRIVE ANALYSIS}

Current drive calculations have been done for lower hybrid and ICRF fast wave schemes. Electron cyclotron current drive is being examined for stabilization of neoclassical tearing modes at the lower fields of the AT plasmas. Neutral beam injection is not presently part of the current drive capability for FIRE, however, it is still being considered for heating/current drive/rotation due to its importance in present experiments for MHD stability, transport, and diagnostics.

Analysis of the ICRF fast wave current drive[8] was done for the 2 strap antennas planned for ion heating, with frequency range of 70-115 MHz and $20 \mathrm{MW}$ installed power occupying 4 ports. Both ray-tracing and full wave analyses were done and shown to be in reasonable agreement. Two issues were found, 1) the launched spectrum only provided about $40 \%$ of the power in the good current drive part of the spectrum, and 
2) there could be significant ion absorption. The second problem was removed by expanding the frequency range to lower frequencies $(70 \mathrm{MHz}$ ) allowing up to $85 \%$ absorption on electrons. The first problem was examined two ways, by increasing the number of straps to 4 in the existing ports, which increased the $\mathrm{CD}$ efficiency by $50 \%$, and expanding the antennas between ports to create a more continuous antenna with the fraction of power in the good part of the spectrum up to $77 \%$, nearly doubling the $\mathrm{CD}$ efficiency. The base case provides $150-200 \mathrm{kA}$ of on-axis current for $20 \mathrm{MW}$ injected, and the spectrum improvements are being pursued to reduce the power required. Typically the AT plasmas require about 100-150 kA of current on-axis.

The lower hybrid current drive calculations were done with LSC[9], ACCOME[10], and CURRAY[11]. The minimum frequency was chosen to be above twice the maximum lower hybrid frequency expected. Values used in the analysis were 4.6 and $5.6 \mathrm{GHz}$, the former being that chosen for the Alcator $\mathrm{C}$-Mod launcher. The parallel wave spectrum was chosen to minimize mode conversion at low $\mathrm{n} \|$, while trying to get the deepest penetration. The spectrum is peaked at about $\mathrm{n} \|=$ 2.0. The width of the spectrum was taken at 0.3 , which was also typical of that expected from the C-Mod design. For a peak density of $4.4 \times 10^{20} / \mathrm{m}^{3}$, a peak temperature of $15 \mathrm{keV}$, peak to average density of 1.4 , and toroidal field of $6.5 \mathrm{~T}$, ACCOME found a CD efficiency $\left(\mathrm{n}_{20} \mathrm{RI}_{\mathrm{LH}} / \mathrm{P}_{\mathrm{LH}}\right)$ of $0.16 \mathrm{~A} / \mathrm{W}$ $\mathrm{m}^{2}$. A CD efficiency of $0.25 \mathrm{~A} / \mathrm{W}-\mathrm{m}^{2}$ is found at $8.5 \mathrm{~T}$. Several spectrum variations were analyzed, as well as several density and temperature variations. The LH current deposition can be seen in Figure 4. The lower hybrid deposition does reach the tail of the alpha particle birth profile, but only 1 MW out of $20 \mathrm{MW}$ was absorbed.

The EC methods for current drive are difficult at FIRE parameters, due to high density and toroidal field. However, at the lower fields of the AT, the $170 \mathrm{GHz}$ development for high power $\mathrm{CW}$ sources on ITER can be utilized. FIRE must use LFS launched O-mode at the fundamental, which at 170 $\mathrm{GHz}$ accesses $\mathrm{R}+\mathrm{a} / 4$ at $6.5 \mathrm{~T}$. The electron plasma frequency is greater than or equal to the cyclotron frequency over about $2 / 3$ of the plasma minor radius, cutting off the EC waves, further restricting access to the plasma. The EC launchers need to be located at the top/bottom of the ports to access the regions where the waves can be absorbed. The LFS deposition will degrade CD efficiency due to trapped particles, however, it was found[12] that the Ohkawa effect can drive current on the LFS as efficiently as ECCD on the HFS. For FIRE, at $150 \mathrm{GHz}$ with midplane launch, $10 \mathrm{kAwas}$ driven for $5 \mathrm{MW}$ of injected power, at 0.9-0.95, which is where the 5,2 and 3,1 islands are typically located.

The current and power requirements are projected based on present experimental stabilization of saturated $(3,2)$ islands on ASDEX-U and DIII-D, along with the CD efficiency from the EC calculations in ref.[12] for FIRE parameters. The current requirement scales like $\mathrm{Ip}^{*} \beta_{\mathrm{N}}{ }^{2}$, which results in about $200 \mathrm{kA}$ being required to suppress an NTM in FIRE's AT plasma. This corresponds to about $100 \mathrm{MW}$ of power, which is excessive. However, these modes can be stabilized before they saturate, which requires 2-4 times less current and power, since the current diffusion time in these plasmas is about $8 \mathrm{~s}$.

The safety factor in FIRE AT plasmas will be above 2 everywhere, so that the $(5,2)$ and $(3,1)$ are the lowest order islands that would appear. There are not enough experiments in this regime to determine whether these NTM's appear or degrade confinement significantly. Launcher design, ray propagation, and CD optimization is continuing.

\section{DYNAMIC EVOLUTION OF ADVANCED TOKAMAK PLASMAS}

The Tokamak Simulation Code[11] (TSC) is used to simulate the discharge, with the LSC ray tracing package connected for the lower hybrid current drive calculations. The fast wave is not calculated self-consistently, but modelled as a prescribed profile and current drive efficiency. The primary goal is to establish quasi-stationary burning plasmas for the flattop, where the current and safety factor profiles do not significantly change. Although inductive and non-inductive current drive are used to ramp the plasma current up, the flattop plasma has $100 \%$ non-inductive current provided by the combination of bootstrap, lower hybrid, and fast wave current.

The parameters for this simulation are $\mathrm{Bt}=6.5 \mathrm{~T}, \mathrm{Ip}=4.5$ $\mathrm{MA}, \beta \mathrm{N}=4.2, \beta=4.7 \%, \mathrm{I}(\mathrm{BS})=3.5 \mathrm{MA}, \mathrm{I}(\mathrm{LH})=0.82$ $\mathrm{MA}, \mathrm{I}(\mathrm{FW})=0.18 \mathrm{MA}$, and $\mathrm{Q} \approx 5$ with $\mathrm{H} 98(\mathrm{y}, 2)=1.7$. The plasma current is ramped up over $10 \mathrm{~s}$, and the flattop is $31 \mathrm{~s}$ long. Shown in Figures 3 and 4 are some time histories and flattop profiles for this simulation. A maximum of $20 \mathrm{MW}$ of ICRF power, to drive the small on-axis current and heat ions, is injected during the rampup, and dropped to $7 \mathrm{MW}$ in the flattop. The $\mathrm{LH}$ power increases to $25 \mathrm{MW}$ during rampup and remains there for the flattop. This provides both off-axis current drive and heating to electrons. The density relative to Greenwald density reaches 0.85 , with the peak density reaching $4.4 \times 10^{\wedge} 20 / \mathrm{m}^{\wedge} 3$, and with a peak to average density of 1.4. The energy confinement time in flattop is 0.7 $\mathrm{s}$, which is 1.7 times the ITER98 $(\mathrm{y}, 2)$ scaling. The peak electron temperature reaches $16 \mathrm{keV}$, while that for the ions is $14 \mathrm{keV}$, and the peak to average temperatures for both species is 2.15. About $19 \mathrm{~V}$-s were used in the plasma current rampup, which is about $46 \%$ of that required to ramp to the full current inductively. The flattop alpha power was $30 \mathrm{MW}$. The radiation power loss was $15 \mathrm{MW}$. The impurity is taken to be $2 \%$ Be and $0.3 \% \mathrm{Ar}$, which resulted in a $Z_{\text {eff }}$ of 2.3 with the He included. The volume average He density was $1.82 \times 10^{\wedge} 19 / \mathrm{m}^{\wedge} 3$. The bootstrap current fraction is $77 \%$, with $\mathrm{LH}$ providing $19 \%$ and FW the remaining $4 \%$. The high bootstrap fraction is due to a $\beta_{\mathrm{N}}$ of 4.2 in combination with a stronger density peaking than is typical of standard ELMy Hmodes. Although pellet fueling might provide some peaking, it is expected that the formation of an internal transport barrier will provide more significant peaking. Transport calculations 
to predict the formations of an ITB are underway. The density peaking is also important for efficient LH current drive, whose efficiency scales as $\mathrm{T} / \mathrm{n}$, by keeping the density lower in the deposition region.

\section{DISCUSSION}

The FIRE burning plasma design is capable of producing a wide range of AT plasma configurations, with $Q \geq 5$. Systems analysis has identified viable operating points that reach 1-5 current diffusion times and $\beta_{\mathrm{N}}$ values of 3.0-4.5, that remain within the engineering limits of the device. Equilibrium and ideal MHD stability analysis show that high $\beta$ and high bootstrap current fractions are accessible with stabilization of the $n=1$ RWM. The RF current drive analysis has demonstrated that FWCD and LHCD are viable noninductive current sources for FIRE's plasma parameters. The study of ECCD stabilization of NTM's will continue. The dynamic simulations have demonstrated that a combination of inductive and noninductive current drive can rampup the plasma current, resulting in a fully noninductive quasistationary flattop plasma in timescales that are provided by the cryogenic copper TF/PF coils and nuclear heating in FIRE. The PF coils provide the entire defined operating space: 0.35 $\leq \operatorname{li}(3) \leq 0.6,2.5 \leq \beta_{\mathrm{N}} \leq 5.0,7.5 \leq \psi(\mathrm{Wb}) \leq 17.5$, with $\mathrm{Ip} \leq$ 5.0 MA, without exceeding stress and thermal limits, up to flattop times of $40 \mathrm{~s}$.

\section{Supported DOE Contract DE-AC02-76-CHO3073}

\section{REFERENCES}

[1] J. DeLucia, S. C. Jardin, and A. M. M. Todd, "An Iterative Metric Method for Solving the Inverse Tokamak Equilibrium Problem", J. Comp. Phys., vol. 37, pg. 183, 1980.

[2] J. M. Greene and M. S. Greene, "The Second Region of Stability Against Ballooning Modes", Nucl. Fusion, vol. 21, pg. 453, 1981.

[3] R. C. Grimm, R. L. Dewar, and J. Manickam, "Ideal MHD Stability Calculations in Axisymmetric Toroidal Coordinate Systems", J. Comp. Phys., vol. 49, pg. 94, 1983.

[4] C. E. Kessel, J. Manickam, G. Rewoldt, and W. Tang, "Improved Plasma Performance in Tokamaks with Negative Magnetic Shear", Phys. Rev. Lett., vol. 72, pg. 1212, 1994.

[5] A. Bondeson, M. Benda, M. Persson, and M. S. Chu, "Magnetohydrodynamic Beta Limits for Tokamaks with Negative Central Shear", Nucl. Fusion, vol. 37, pg. 1419, 1997.

[6] M. Okabayashi, et al., "Active Feedback Stabilization of the Resistive Wall Mode on the DIII-D Device", Phys. Plasmas, vol. 8, pg. 2071, 2001.

[7] J. Bialek, A. H. Boozer, M. E. Mauel, and G. A. Navratril, "Modelling of Active Control of External Magnetohydrodynamic Instabilities", Phys. Plasmas, vol. 8, pg. 2170, 2001.

[8] D. W. Swain and C. Kessel, "Heating and Current Drive Systems for FIRE AT Operation", in proceedings of this conference.

[9] D. W. Ignat, E. J. Valeo, and S. C. Jardin, "Dynamic Modelling of Lower Hybrid Current Drive", Nucl. Fusion, vol. 34, pg. 837, 1994.

[10] P. T. Bonoli, et al., Nucl. Fusion, vol. 30, pg. 533, 1990.

[11] T. K. Mau, S. S. Chiu, and R. W. Harvey, EPS Topical Conference Abstracts on Radiofrequency Heating and Current Drive of Fusion Devices, Brussels, pg. 181, 1992.

[12] J. Decker, "ECCD for Advanced Tokamak Operations: Fisch-Boozer versus Ohkawa Methods", AIP Proc. of $15^{\text {th }}$ Topical Conference on RF Power in Plasmas, Moran, WY, May 2003, to be published.

[13] S. C. Jardin, N. Pomphrey, and J. Delucia, "Dynamic Modelling of Transport and Position Control of Tokamaks", J. Comp. Phys., vol. 66, pg. 481, 1986.

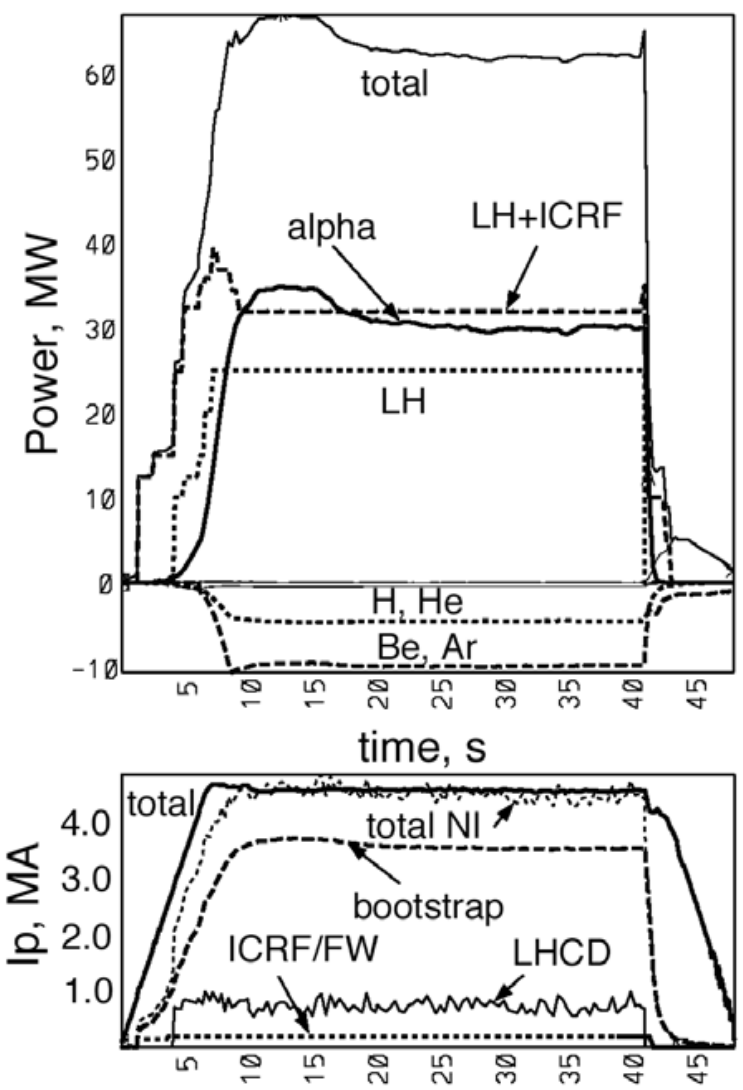

FIGURE 3. Time histories from the TSC-LSC AT simulation, of the various contributions to the plasma current and the powers injected into the plasma.

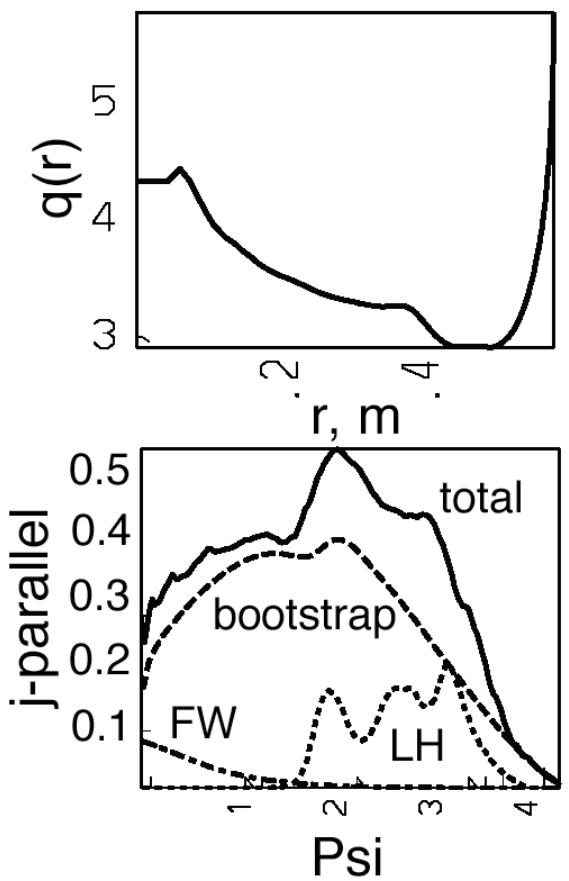

FIGURE 4. The parallel current density profile from the TSC-LSC AT simulation during flattop, showing the $\mathrm{LH}, \mathrm{FW}$, and bootstrap current profiles. The resulting safety factor profile is also shown. 


\section{External Distribution}

Plasma Research Laboratory, Australian National University, Australia

Professor I.R. Jones, Flinders University, Australia

Professor João Canalle, Instituto de Fisica DEQ/IF - UERJ, Brazil

Mr. Gerson O. Ludwig, Instituto Nacional de Pesquisas, Brazil

Dr. P.H. Sakanaka, Instituto Fisica, Brazil

The Librarian, Culham Laboratory, England

Mrs. S.A. Hutchinson, JET Library, England

Professor M.N. Bussac, Ecole Polytechnique, France

Librarian, Max-Planck-Institut für Plasmaphysik, Germany

Jolan Moldvai, Reports Library, Hungarian Academy of Sciences, Central Research Institute for Physics, Hungary

Dr. P. Kaw, Institute for Plasma Research, India

Ms. P.J. Pathak, Librarian, Institute for Plasma Research, India

Ms. Clelia De Palo, Associazione EURATOM-ENEA, Italy

Dr. G. Grosso, Instituto di Fisica del Plasma, Italy

Librarian, Naka Fusion Research Establishment, JAERI, Japan

Library, Laboratory for Complex Energy Processes, Institute for Advanced Study, Kyoto University, Japan

Research Information Center, National Institute for Fusion Science, Japan

Dr. O. Mitarai, Kyushu Tokai University, Japan

Dr. Jiangang Li, Institute of Plasma Physics, Chinese Academy of Sciences, People's Republic of China

Professor Yuping Huo, School of Physical Science and Technology, People's Republic of China

Library, Academia Sinica, Institute of Plasma Physics, People's Republic of China

Librarian, Institute of Physics, Chinese Academy of Sciences, People's Republic of China

Dr. S. Mirnov, TRINITI, Troitsk, Russian Federation, Russia

Dr. V.S. Strelkov, Kurchatov Institute, Russian Federation, Russia

Professor Peter Lukac, Katedra Fyziky Plazmy MFF UK, Mlynska dolina F-2, Komenskeho Univerzita, SK-842 15 Bratislava, Slovakia

Dr. G.S. Lee, Korea Basic Science Institute, South Korea

Institute for Plasma Research, University of Maryland, USA

Librarian, Fusion Energy Division, Oak Ridge National Laboratory, USA

Librarian, Institute of Fusion Studies, University of Texas, USA

Librarian, Magnetic Fusion Program, Lawrence Livermore National Laboratory, USA

Library, General Atomics, USA

Plasma Physics Group, Fusion Energy Research Program, University of California at San Diego, USA

Plasma Physics Library, Columbia University, USA

Alkesh Punjabi, Center for Fusion Research and Training, Hampton University, USA

Dr. W.M. Stacey, Fusion Research Center, Georgia Institute of Technology, USA

Dr. John Willis, U.S. Department of Energy, Office of Fusion Energy Sciences, USA

Mr. Paul H. Wright, Indianapolis, Indiana, USA 
The Princeton Plasma Physics Laboratory is operated by Princeton University under contract with the U.S. Department of Energy.

\author{
Information Services \\ Princeton Plasma Physics Laboratory \\ P.O. Box 451 \\ Princeton, NJ 08543
}

Phone: 609-243-2750

Fax: 609-243-2751

e-mail: pppl_info@pppl.gov

Internet Address: http://www.pppl.gov 